\title{
SUBSTRATOS ALTERNATIVOS NA PRODUÇÃO DE MUDAS DE Chamaecrista desvauxii ${ }^{1}$
}

Marcos Vinicius Winckler Caldeira², William Macedo Delarmelina², Júlio Cézar Tannure Faria² e Ronie Silva Juvanhol ${ }^{2}$

\begin{abstract}
RESUMO - O objetivo deste estudo foi avaliar o potencial da utilização de resíduos orgânicos como componentes do substrato para produção de mudas de Chamaecrista desvauxii, vulgarmente conhecida como rabo-de-pitu, empregada na recuperação de áreas degradadas. Estabeleceram-se os tratamentos utilizando quatro tipos de substrato: lodo de esgoto (LE), casca de arroz carbonizada (CAC), palha de café in natura (PC in natura) e substrato comercial (SC), em diferentes proporções de volume. Quando as mudas atingiram 150 dias de idade, elas foram mensuradas quanto às seguintes características: altura, diâmetro do coleto, relação entre altura e diâmetro do coleto, massa seca da parte aérea, massa seca do sistema radicular, massa seca total, relação entre massa seca da parte aérea e massa seca do sistema radicular e índice de qualidade de Dickson (IQD). Os substratos formulados com lodo de esgoto, casca de arroz carbonizada e palha de café in natura propiciaram os melhores resultados das características avaliadas, sendo o tratamento com $60 \%$ LE + 20\% CAC + $20 \%$ PC in natura o que proporcionou as mais adequadas características morfológicas avaliadas na produção de Chamaecrista desvauxii.
\end{abstract}

Palavras-chave: Características morfológicas, Qualidade de mudas, Resíduos orgânicos, Rabo-de-pitu.

\section{ALTERNATIVE SUBSTRATES IN THE PRODUCTION OF SEEDLINGS OF Chamaecrista desvauxii}

\begin{abstract}
The objective of this study was to evaluate the potential of sewage sludge and organic waste as component of substrate for Chamaecrista desvauxii seedlings production. It was established ten treatments using four types of substrate: sewage sludge, carbonized rice hull, coffee straw and commercial substrate in different proportions. When the seedlings were at three months of age, the following parameters were measured: stem diameter, plant height, ratio between plant height and stem diameter, shoot dry mass, dry mass of root system, total dry mass, dry mass ratio of shoot/root dry mass and Dickson quality index (IQD). The substrates made with sewage sludge, carbonized rice hull and coffee straw provided better results of growth of seedlings. Moreover, the treatment with $60 \%$ sewage sludge $+20 \%$ carbonized rice hull $+20 \%$ coffee straw provided the best development of the morphological characteristics evaluated, and it was recommended for the production of Chamaecrista desvauxii.
\end{abstract}

Keywords: Morphological characteristics, Organic waste, Rabo-de-pitu, Seedling quality.

\footnotetext{
${ }^{1}$ Recebido em 15.02.2012 aceito para publicação em 20.12.2012

${ }^{2}$ Universidade Federal do Espírito Santo, UFES, Brasil. E-mail: <mvwcaldeira@ gmail.com>, <williamdm@ hotmail.com>, <juliocezar14@hotmail.com>,<juliocezar14@hotmail.com>e <ronie_juvanhol@hotmail.com>.
} 


\section{INTRODUÇÃO}

A grande exploração das florestas nativas, seja pela expansão agrícola, seja pela pecuária extensiva, acarreta grande diminuição da cobertura florestal, provocando a degradação e desequilíbrio ambiental. Assim, com o aumento da fiscalização e as exigências de medidas compensatórias houve maior demanda de mudas nativas para recuperação de áreas degradadas.

Basicamente, as mudas de nativas são destinadas para compensar a perda de espécies arbóreas, favorecendo a regeneração vegetal e minimizando os processos de degradação, como erosão, assoreamento e empobrecimento do solo. Nesse contexto, a escolha da Chamaecrista desvauxii é justificável por se tratar de um gênero eminentemente florestal, embora ocorra apenas ou, preferencialmente, a sol pleno, sendo usadas como fixadoras de nitrogênio no solo e indicadas na recuperação de áreas degradadas (FARIA et al., 1989).

Enquanto as mudas permanecem no viveiro, o fator que deverá obrigatoriamente ser levado em consideração é o substrato, que será utilizado na produção de mudas, devendo possuir características como consistência, boa estrutura, alta capacidade de retenção de água e alta porosidade. O substrato não deve se expandir, contrair ou apresentar substâncias tóxicas, devendo ser disponível e padronizado (GONÇALVES; POGGIANI, 1996). Nesse âmbito, são de grande importância estudos relacionados aos componentes do substrato, sendo necessária a promoção de resíduos orgânicos e industriais para obtenção de mudas com maior qualidade e com menor custo. Com isso, o lodo de esgoto surge como alternativa viável para ser utilizado como componente de substrato para produção de mudas (PEDROZA et al., 2003), pois melhora as propriedades físicas, químicas e biológicas do substrato, acarretando em mudas de melhor qualidade para serem levadas a campo (GUERRINI; TRIGUEIRO, 2004; KRATZ, 2011).

Um material muito utilizado na formulação de substrato é o resíduo gerado a partir do processamento industrial do arroz. Nos últimos anos, a casca de arroz passou a ser intensamente utilizada como substrato para o crescimento de plantas, por ser facilmente encontrada e por possuir características favoráveis ao desenvolvimento vegetal (TRIGUEIRO; GUERRINI, 2003). Esse material apresenta alta capacidade de retenção de água, drenagem rápida e eficiente, proporcionando boa oxigenação para as raízes, elevado espaço de aeração ao substrato, resistência à decomposição, relativa estabilidade de estrutura, baixa densidade e $\mathrm{pH}$ próximo à neutralidade (SOARES et al., 2012). Outro resíduo orgânico com potencial de utilização é a casca do café produzida durante o seu beneficiamento. Esse resíduo, por ser de natureza orgânica, pode ser utilizado na agricultura como fertilizante em lavouras e pelos viveiristas na produção de mudas.

O objetivo deste trabalho foi avaliar o potencial de utilização do lodo de esgoto, da casca de arroz e da palha de café como componentes do substrato para produção de mudas de Chamaecrista desvauxii.

\section{MATERIAL E MÉTODOS}

A produção de mudas de Chamaecrista desvauxii, vulgarmente conhecida como rabo-de-pitu, utilizando lodo de esgoto (LE), casca de arroz carbonizada (CAC) e palha de café in natura (PC in natura), foi conduzida no viveiro florestal do Centro de Ciências Agrárias da Universidade Federal do Espírito Santo, no Município de Alegre, ES (CCA-UFES). O clima da região enquadra-se no tipo Cwa (inverno seco e verão chuvoso), de acordo com a classificação de Köppen, sendo a temperatura média anual de $24,1^{\circ} \mathrm{C}$, com máximas diárias de $31{ }^{\circ} \mathrm{C}$ e mínimas de $20,2^{\circ} \mathrm{C}$ e precipitação anual média de $1.104 \mathrm{~mm}$ (MAIA et al., 2007).

O lodo de esgoto utilizado foi procedente da Empresa de Saneamento Foz do Brasil, prestadora de serviços para o Município de Cachoeiro de Itapemirim, ES, produzidos na Estação de Tratamento de Esgoto de Pacotuba, ES, cujos teores de metais pesados estão apresentados na Tabela 1, que de acordo com a Resolução CONAMA - 375/2006 está apto para uso em ambientes agrícolas.

A casca de arroz carbonizada com granulometria ente 1 e $2 \mathrm{~mm}$ (original) e o substrato comercial foram procedentes da Fibria S.A. (Unidade Aracruz), além da palha de café in natura com granulometria de $4 \mathrm{~mm}$, adquirida na região de Muniz Freire, ES.

Os tratamentos consistiram dos seguintes componentes: lodo de esgoto (LE), casca de arroz carbonizada (CAC), palha de café in natura (PC in natura) e substrato comercial (SC) composto de $60 \%$ de composto de casca de pinus, $15 \%$ de vermiculita e $25 \%$ de húmus mais terra vegetal. Foram testadas as seguintes proporções de lodo de esgoto:palha de café in natura:casca de arroz carbonizada (v:v:v): T1-

Revista Árvore, Viçosa-MG, v.37, n.1, p.31-39, 2013

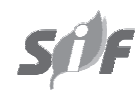


100:00:00; T2- 80:10:10; T3- 60:20:20; T4- 40:30:30; T520:40:40; T6- 80:20:00; T7- 60:40:00; T8- 40:60:00; T920:80:00; e T10- substrato comercial (testemunha).

$\mathrm{O}$ experimento foi instalado em delineamento inteiramente casualizado, constituído de 10 tratamentos com seis repetições, cada uma com oito plantas.

Para determinação dos teores totais de nutrientes, macro e micro, bem como os teores de matéria orgânica e a relação $\mathrm{C} / \mathrm{N}$, dos componentes presentes nos substratos, foi utilizada a metodologia proposta pela Embrapa (1997) (Tabela 2). As análises foram realizadas no Laboratório de Recursos Hídricos do DCFM/CCAUFES, Jerônimo Monteiro, ES. Os resíduos foram submetidos às análises antes do plantio das mudas.

A caracterização física dos resíduos foi realizada no Laboratório de Substratos do Departamento de

Tabela 1 - Teores $\left(\mathrm{mg} \mathrm{dm}^{-3}\right)$ de metais pesados no lodo de esgoto doado pela Foz do Brasil S.A., na estação de tratamento de esgoto de Cachoeiro de Itapemirim, ES.

Table 1 -Content $\left(\mathrm{mg} \mathrm{dm}^{-3}\right)$ of heavy metals in sewage sludge donated by Foz do Brasil S.A. in sewer treatment plant in Itapemirim, ES.

\begin{tabular}{ccc}
\hline Parâmetros & $\begin{array}{c}\text { Resultados } \\
\text { analíticos }^{\mathbf{1}}\end{array}$ & $\begin{array}{c}\text { Resolução CONAMA } \\
-375 / 2006\end{array}$ \\
\hline $\mathrm{Ar}$ & $<0,5$ & 41 \\
$\mathrm{Ba}$ & 156 & 1300 \\
$\mathrm{Cd}$ & $<0,053$ & 39 \\
$\mathrm{~Pb}$ & 29 & 300 \\
$\mathrm{Cu}$ & 98 & 1500 \\
$\mathrm{Cr}$ & 26 & 1000 \\
$\mathrm{Mb}$ & 3,5 & 50 \\
$\mathrm{Ni}$ & 11 & 420 \\
$\mathrm{Se}$ & $<0,5$ & 100 \\
\hline
\end{tabular}

${ }^{1}$ Resultados fornecidos pela Foz do Brasil S.A.
Horticultura e Silvicultura da Universidade Federal do Rio Grande do Sul (UFRGS), conforme metodologia descrita na Instrução Normativa ${ }^{\circ} 17$, do Ministério da Agricultura, Pecuária e Abastecimento, 2007.

As análises físicas realizadas corresponderam à determinação da densidade do substrato (DENS), macroporosidade (Macrop), microporosidade (Microp) e volume total de poros (VTP) (Tabela 3).

As sementes de Chamaecrista desvauxii foram provenientes da Reserva Natural Vale e passaram por um processo de quebra de dormência em ácido sulfúrico (95-97\%) por $10 \mathrm{~min}$. Posteriormente, foram desinfestadas com peróxido de hidrogênio (30\%) por 2 min e em seguida lavadas com água estéril.

Os substratos correspondentes aos tratamentos foram colocados em tubetes com capacidade para $120 \mathrm{~cm}^{3}$, os quais foram acondicionados em bandejas de polipropileno com capacidade para 54 tubetes. As bandejas foram, por sua vez, dispostas em canteiros suspensos a $80 \mathrm{~cm}$ do solo, na casa de sombra coberta com tela permitindo a passagem de $50 \%$ da luminosidade. A semeadura foi realizada diretamente, sendo semeadas três sementes por tubete. Após a emergência ( \pm 20 dias) foi realizado o desbaste, deixando-se uma muda por recipiente. Para garantir o bom suprimento de nutrientes nas mudas, todos os tratamentos receberam fertilização de base: $750 \mathrm{~g}$ de sulfato de amônio, $1.667 \mathrm{~g}$ de superfosfato simples e $172 \mathrm{~g}$ de cloreto de potássio por metro cúbico de substrato (GONÇALVES et al., 2000).

Quando as mudas atingiram 150 dias de idade, foram mensuradas as seguintes características: altura (H), diâmetro do coleto (DC), relação entre altura da

Tabela 2 - Teores totais de macro e micronutrientes e matéria orgânica (MO) e relação C/N do substrato comercial e dos resíduos orgânicos.

Table 2 - Total content of macro and micronutrients, organic matter (OM) and C/N ratio of commercial substrate and organic waste.

\begin{tabular}{|c|c|c|c|c|c|c|c|c|c|c|c|c|c|}
\hline \multirow{2}{*}{ Materiais componentes } & $\mathrm{N}$ & $\mathrm{P}$ & $\mathrm{K}$ & $\mathrm{Ca}$ & $\mathrm{Mg}$ & $\mathrm{S}$ & $\mathrm{Zn}$ & $\mathrm{Fe}$ & $\mathrm{Mn}$ & $\mathrm{Cu}$ & B & MO & $\mathrm{C} / \mathrm{N}$ \\
\hline & & \multicolumn{4}{|c|}{$\mathrm{g} \mathrm{kg}^{-1}$} & \multicolumn{6}{|c|}{$\mathrm{mg}$} & \multicolumn{2}{|c|}{$\mathrm{kg}^{-1} \mathrm{~g} \mathrm{~kg}^{-1}$} \\
\hline $\mathrm{SC}^{1}$ & 8,8 & 1,6 & 1,2 & 8,3 & 4,1 & 0,06 & 44 & 9200 & 199 & 10 & 14,0 & 145,9 & 9,6 \\
\hline $\mathrm{LE}^{2}$ & 13,3 & 2,5 & 0,8 & 8,9 & 2,4 & 0,14 & 231 & 17480 & 157 & 53 & 8,0 & 65,5 & 2,9 \\
\hline $\mathrm{CAC}^{3}$ & 4,6 & 1,1 & 6,5 & 2,1 & 1,0 & 0,06 & 44 & 506 & 492 & 8 & 6,0 & 320,5 & 40,4 \\
\hline $\mathrm{PC}$ in natura ${ }^{4}$ & 11,6 & 1,1 & 0,8 & 29,1 & 4,2 & 0,40 & 25 & 7625 & 79 & 6 & 11,1 & 300,0 & 15,5 \\
\hline
\end{tabular}

${ }^{1}$ Substrato comercial. ${ }^{2}$ Lodo de esgoto. ${ }^{3}$ Casca de arroz carbonizada. ${ }^{4}$ Palha de café in natura. 
Tabela 3 - Valores médios de volume total de poros (VTP), macroporosidade (Macrop) e microporosidade (Microp) e densidade aparente (DENS) dos resíduos orgânicos.

Table 3 - Mean values of total pore volume (TPV), macroporosity (Macrop) and microporosity (Microp) and density (DENS) of commercial substrate and organic waste.

\begin{tabular}{|c|c|c|c|c|}
\hline \multirow{2}{*}{ Materiais componentes } & VTP & Macrop & Macrop & \multirow{2}{*}{$\begin{array}{l}\text { DENS } \\
\mathrm{g} \mathrm{cm}^{-3}\end{array}$} \\
\hline & & $\%$ & & \\
\hline $\mathrm{SC}^{1}$ & 85 & 33 & 52 & 0,32 \\
\hline $\mathrm{LE}^{2}$ & 75 & 23 & 52 & 0,21 \\
\hline $\mathrm{CAC}^{3}$ & 71 & 55 & 16 & 0,12 \\
\hline $\mathrm{PC}$ in natura ${ }^{4}$ & 44 & 23 & 21 & 0,02 \\
\hline
\end{tabular}

${ }^{1}$ Substrato comercial. ${ }^{2}$ Lodo de esgoto. ${ }^{3}$ Casca de arroz carbonizada. ${ }^{4}$ Palha de café in natura.

parte aérea e diâmetro do coleto (RHD), massa seca da parte aérea (MSPA), massa seca do sistema radicular (MSR), massa seca total (MST), relação entre a massa seca da parte aérea e a massa seca do sistema radicular (RMSPAR) e índice de qualidade de Dickson (IQD).

O diâmetro do coleto foi obtido com paquímetro digital com precisão de $0,01 \mathrm{~mm}$ e a altura com régua milimetrada, tomando-se como padrão a gema terminal. A massa seca da parte aérea e a massa seca do sistema radicular foram determinadas por meio da pesagem das respectivas partes vegetais, após a secagem do material por um período de aproximadamente $72 \mathrm{~h}$, em estufa de circulação de ar forçada a $70^{\circ} \mathrm{C}$. O índice de qualidade de Dickson foi obtido pela fórmula de Dickson et al. (1960):

$$
\mathrm{IQD}=\frac{\operatorname{MST}_{(\mathrm{g})}}{\mathrm{H}_{(\mathrm{cm})} / \mathrm{DC}_{(\mathrm{mm})}+\operatorname{MSPA}_{(\mathrm{g})} / \operatorname{MSR}_{(\mathrm{g})}}
$$

em que:

$\operatorname{MST}(\mathrm{g})=$ massa seca total;

$\mathrm{H}(\mathrm{cm})=$ altura;

$\mathrm{DC}(\mathrm{mm})=$ diâmetro do coleto;

$\operatorname{MSPA}(\mathrm{g})=$ massa seca da parte aérea; e

$\operatorname{MSR}(\mathrm{g})=$ massa seca da raiz.

As características analisadas foram submetidas à análise estatística, e para comparação de médias dos tratamentos utilizou-se o teste de Scott-Knott a 5\% de significância.

Revista Árvore, Viçosa-MG, v.37, n.1, p.31-39, 2013

\section{RESULTADOS}

Observa-se, nas Tabelas 4 e 5, que mudas produzidas nos tratamentos formulados com lodo de esgoto apresentaram resultados estatisticamente superiores de todas as características de crescimento analisadas, em comparação com o tratamento-testemunha com apenas substrato comercial em sua constituição.

As maiores alturas, 63,26 e 63,91 cm, foram encontradas nas mudas produzidas com as formulações dos tratamentos $\mathrm{T} 2(80 \% \mathrm{LE}+10 \% \mathrm{CAC}+10 \% \mathrm{PC}$ in natura) e T3 (60\% LE + 20\% CAC $+20 \%$ PC in natura), respectivamente, sem diferenças estatísticas entre si (Tabela 4). Em ambos os casos foram formulados substratos com três tipos de resíduos diferentes: lodo de esgoto, casca de arroz carbonizada e palha de café. Mudas do tratamento- testemunha (T10) apresentaram média de altura inferior à dos demais tratamentos, que continham resíduos orgânicos, demonstrando, assim, o efeito positivo dos substratos formulados com lodo de esgoto, casca de arroz carbonizada e palha de café in natura.

Neste estudo, as médias do diâmetro do coleto variaram entre 0,77 e $3,26 \mathrm{~mm}$. Semelhante aos resultados da altura, a menor média do diâmetro do coleto foi observada nas mudas produzidas no tratamento T10 (substrato comercial). A maior média foi apresentada pelo tratamento composto com $60 \%$ de lodo de esgoto $+20 \%$ de casca de arroz carbonizada $+20 \%$ de palha de café in natura (T3), não diferindo estatisticamente dos tratamentos T1, T2, T5, T6, T7 e T8.

O grande crescimento da altura não acompanhado pelo incremento em diâmetro fez que as médias da relação altura da parte aérea/diâmetro do coleto ficassem muito elevadas. Neste estudo, os valores de RHD ficaram acima de 12,28 , sendo o valor máximo observado no tratamento $\mathrm{T} 2(80 \% \mathrm{LE}+10 \% \mathrm{CAC}+10 \% \mathrm{PC}$ in natura $)$, com média de 20,86.

Os resultados positivos do uso de componentes alternativos na produção de mudas de C. desvauxii podem ser observados quando se analisa o índice de qualidade de Dickson. Para esse índice, o tratamento $\mathrm{T} 3(60 \% \mathrm{LE}+20 \% \mathrm{CAC}+20 \% \mathrm{PC}$ in natura $), \mathrm{T} 5(20 \%$ $\mathrm{LE}+40 \% \mathrm{CAC}+40 \% \mathrm{PC}$ in natura) e $\mathrm{T} 7(60 \% \mathrm{LE}$ $+40 \%$ PC in natura) apresentaram médias estatisticamente superiores, enquanto mudas do tratamento T10 (substrato comercial) proporcionaram IQD abaixo do que o observado nos outros substratos. 
No que se refere à massa seca da parte aérea, houve diferença estatística nos tratamentos testados (Tabela 5). As médias desta característica variaram entre 0,299 e 2,324 g por muda. A maior média foi proporcionada no tratamento em que se utilizaram $60 \% \mathrm{LE}+20 \%$ CAC $+20 \%$ PC in natura (T3). Mudas produzidas com substrato comercial apresentaram valores de massa seca da parte aérea inferiores em relação aos demais tratamentos, devendo dar preferência aos substratos com componentes alternativos na produção de mudas de Chamaecrista desvauxii.

Quanto aos resultados correspondentes à massa seca da raiz das mudas de C. desvauxii analisadas, observaram-se valores significativamente superiores nos tratamentos T3 e T5, este último com a maior média, com o valor de $0,777 \mathrm{~g}$.

Com relação à massa seca total, a maior média foi de 3,054 g, referente ao tratamento T3 com $60 \% \mathrm{LE}$ $+20 \%$ CAC $+20 \%$ PC in natura. Essa característica resultou da soma entre a massa seca da parte aérea e a da massa seca da raiz.

Quando a característica avaliada foi a relação entre a massa seca da parte aérea e a massa seca da raiz, todos os tratamentos formulados com os componentes alternativos apresentaram resultados superiores, em comparação com o tratamento T10, com apenas substrato comercial, segundo o teste de Scott-Knott $(\mathrm{P}>0,05)$.

Tabela 4 - Altura (H), diâmetro do coleto (DC), relação altura/diâmetro (RHD) e índice de qualidade de Dickson (IQD) de mudas de Chamaecrista desvauxii aos 150 dias de idade.

Table 4 - Plant height $(H)$, collar diameter $(C D)$, plant height/stem diameter ratio (HSR) and the quality index of Dickson (QID) of Chamaecrista desvauxii seedlings at 150 days of age.

\begin{tabular}{lccc}
\hline Tratamento & H $(\mathrm{cm})$ & DC $(\mathrm{mm})$ & RHD \\
\hline T1 (100\%LE) & $55,49 \mathrm{~b}$ & $3,11 \mathrm{a}$ & $17,98 \mathrm{c}$ \\
T2 (80\%LE+10\%CAC+10\%PC in natura) & $63,26 \mathrm{a}$ & $3,05 \mathrm{a}$ & $20,86 \mathrm{a}$ \\
T3 (60\%LE+20\%CAC+20\%PC in natura) & $63,91 \mathrm{a}$ & $3,26 \mathrm{a}$ & $19,71 \mathrm{~b}$ \\
T4 (40\%LE+30\%CAC+30\%PC in natura) & $55,18 \mathrm{~b}$ & $2,93 \mathrm{~b}$ & $18,97 \mathrm{~b}$ \\
T5 (20\%LE+40\%CAC+40\%PC in natura) & $55,58 \mathrm{~b}$ & $3,21 \mathrm{a}$ & $17,35 \mathrm{c}$ \\
T6 (80\%LE+20\%PC in natura) & $55,12 \mathrm{~b}$ & $3,12 \mathrm{a}$ & $17,77 \mathrm{c}$ \\
T7 (60\%LE+40\%PC in natura) & $55,25 \mathrm{~b}$ & $3,16 \mathrm{a}$ & $0,13 \mathrm{a}$ \\
T8 (40\%LE+60\%PC in natura) & $51,38 \mathrm{c}$ & $3,21 \mathrm{a}$ & $0,11 \mathrm{~b}$ \\
T9 (20\%LE+80\%PC in natura) & $47,25 \mathrm{~d}$ & $2,76 \mathrm{~b}$ & $16,12 \mathrm{~d}$ \\
T10 (Substrato comercial) & $9,44 \mathrm{e}$ & $0,77 \mathrm{c}$ & $0,12 \mathrm{a}$ \\
CV\% & 6,43 & 10,73 & $0,11 \mathrm{~b}$ \\
\hline
\end{tabular}

Médias seguidas da mesma letra na coluna não diferem estatisticamente entre si, pelo teste de Scott-Knott (P>0,05).

Tabela 5 - Massa seca de parte aérea (MSPA), massa seca radicular (MSR), massa seca total (MST) e relação massa seca da parte aérea/raiz (RMSPAR) de mudas de Chamaecrista desvauxii aos 150 dias de idade.

Table 5 - Shoot dry mass (SDM), dry mass of roots (DMR), total dry mass (TDM) and dry mass ratio of shoot/root dry mass (DMRSRDM) of Chamaecrista desvauxii seedlings at 150 days of age.

\begin{tabular}{lccc}
\hline Tratamento & MSPA $(\mathrm{g})$ & MSR $(\mathrm{g})$ & $\mathrm{MST}(\mathrm{g})$ \\
\hline T1 (100\%LE) & $1,924 \mathrm{~b}$ & $0,544 \mathrm{c}$ & $2,468 \mathrm{c}$ \\
T2 (80\%LE+10\%CAC+10\%PC in natura) & $1,819 \mathrm{c}$ & $0,627 \mathrm{~b}$ & $2,447 \mathrm{c}$ \\
T3 (60\%LE+20\%CAC+20\%PC in natura) & $2,324 \mathrm{a}$ & $0,730 \mathrm{a}$ & $3,054 \mathrm{a}$ \\
T4 (40\%LE+30\%CAC+30\%PC in natura) & $1,642 \mathrm{c}$ & $0,650 \mathrm{~b}$ & $2,292 \mathrm{c}$ \\
T5 (20\%LE+40\%CAC+40\%PC in natura) & $1,981 \mathrm{~b}$ & $0,777 \mathrm{a}$ & $2,758 \mathrm{~b}$ \\
T6 (80\%LE+20\%PC in natura) & $1,798 \mathrm{c}$ & $0,477 \mathrm{c}$ & $2,276 \mathrm{c}$ \\
T7 (60\%LE+40\%PC in natura) & $1,993 \mathrm{~b}$ & $0,571 \mathrm{c}$ & $2,564 \mathrm{c}$ \\
T8 (40\%LE+60\%PC in natura) & $1,689 \mathrm{c}$ & $0,522 \mathrm{c}$ & $2,52 \mathrm{a}$ \\
T9 (20\%LE+80\%PC in natura) & $1,382 \mathrm{~d}$ & $0,537 \mathrm{c}$ & $3,77 \mathrm{a}$ \\
T10 (Substrato comercial) & $0,099 \mathrm{e}$ & $0,108 \mathrm{~d}$ & $3,913 \mathrm{~d}$ \\
CV\% & 22,11 & 28,86 & $0,208 \mathrm{e}$ \\
\hline
\end{tabular}

Médias seguidas da mesma letra na coluna não diferem estatisticamente entre si, pelo teste de Scott-Knott (P>0,05). 


\section{DISCUSSÃO}

Neste estudo, o crescimento das características morfológicas avaliadas foram superiores quando se utilizaram proporções elevadas de lodo de esgoto (60\%), juntamente com os substratos casca de arroz carbonizada e palha de café in natura. Esses resultados provavelmente ocorreram em razão da maior disponibilidade de nutrientes encontrados no lodo de esgoto e na palha de café in natura (Tabela 2) associada à melhoria das características físicas dos substratos, propiciada pelos componentes menos densos e que atribuem maior porosidade ao substrato (Tabela 3 ). Porém, na Tabela 3 verificam-se valores de densidade inadequados de todos os componentes dos substratos, em comparação com os valores propostos por Gonçalves e Poggiani (1996), que mencionaram a escala de valores entre 0,45 e $0,55 \mathrm{~g} \mathrm{~cm}^{-3}$. Entretanto, neste estudo os componentes dos substratos foram analisados de forma individual, o que não fornece informações suficientes sobre as características físicas desses componentes.

Resultados semelhantes aos deste estudo também foram encontrados por Maia (1999) utilizando solo, lodo de esgoto e casca de Pinus como substrato. Esse autor comprovou que a presença de solo no substrato é dispensável e o lodo de esgoto, por sua vez, não deve ser usado puro, apesar de a sua relativa fertilidade em razão, provavelmente, da sua baixa porosidade, provocando compactação do substrato. No mesmo sentido, Oliveira et al. (2008) averiguaram que os níveis adequados de todas as características físicas (retenção de água, densidade do solo, proporção de macroporos e microporos) proporcionaram melhores condições para o crescimento e desenvolvimento de Acacia holocericea A. Cunn.

Para Gomes et al. (2002), a altura da planta pode ser medida para avaliar a qualidade de mudas, por considerar essa característica de fácil mensuração. Contudo, recomendaram que os valores devam ser analisados combinados com outras características. Os resultados positivos em altura encontrados nos tratamentos T2 e T3 provavelmente foram devidos ao bom fornecimento de matéria orgânica (MO) proporcionado pelos componentes palha de café e casca de arroz carbonizada, associados a um adequado nível de porosidade oferecido pela casca de arroz carbonizada, considerada material leve e poroso (GONÇALVES; POGGIANI, 1996; GUERRINI; TRIGUEIRO, 2004).
Faustino et al. (2005) também verificaram que o incremento em altura está relacionado ao acréscimo de MO no substrato.

Com relação ao diâmetro do coleto, Daniel et al. (1997) comentaram que essa característica, em geral, é a mais observada para indicar a capacidade de sobrevivência das mudas no campo, devendo ser maior que $2 \mathrm{~mm}$. Assim, pode-se concluir que apenas o tratamento T10 não atingiu o limite inferior proposto. Valores próximos aos deste estudo foram encontrados por Kratz (2011), em que mudas de Eucalyptus benthamii apresentaram diâmetro de coleto médio de 1,70 mm aos 90 dias utilizando como substrato fibra de coco, casca de arroz carbonizada, lodo de esgoto e casca de pinus semidecomposta em diferentes formulações.

O valor da relação altura da planta e diâmetro é considerado um dos mais precisos e fornece informações sobre quanto delgada está a muda (CARNEIRO, 1995). Verificou-se que neste estudo a menor média dessa relação foi de 12,28, sendo muito acima dos limites propostos por Carneiro (1995), que relatou que deve situar-se entre 5,4 e 8,1 . Os altos valores encontrados neste trabalho foram provavelmente devidos aos altos níveis de $\mathrm{N}$ que tendem a promover maior crescimento em altura e menor em diâmetro de coleto (CARNEIRO, 1995; MARQUES et al., 2009), o que acarreta baixo nível de robustez da muda e, consequentemente, poderá diminuir a capacidade de sobrevivência desta no campo.

Para o índice de qualidade de Dickson, Gomes et al. (2002) observaram em E. grandis que, quanto maior o valor desse índice, melhor o padrão de qualidade das mudas. Bernardino et al. (2005), avaliando a qualidade de mudas de Anadenanthera macrocarpa (Benth.), também afirmaram que as mudas com maior IQD são classificadas como de melhor qualidade. Comparando os valores de Chamaecrista desvauxii com os propostos por Hunt (1990), que estabeleceu o valor mínimo de 0,20 para esse índice, todos os tratamentos não apresentaram resultados satisfatórios, sendo 0,14 a maior média, com $20 \% \mathrm{LE}+40 \% \mathrm{CAC}+40 \% \mathrm{PC}$ (T5).

Com base em alguns estudos, é possível observar que o IQD pode variar em função da espécie, do manejo das mudas no viveiro, do tipo e proporção do substrato, do volume do recipiente e, principalmente, de acordo com a idade em que a muda foi avaliada (KRATZ, 2011; GOMES et al., 2002; CALDEIRA et al., 2008a,b).

Revista Árvore, Viçosa-MG, v.37, n.1, p.31-39, 2013 
Nóbrega et al. (2007), avaliando o crescimento de mudas de aroeira (Schinus terebynthifolius) submetidas a diferentes doses de terra de subsolo e lodo de esgoto (100:0; 80:20; 60:40; 40:60; e 20:80) sem adubação mineral, constataram que o lodo de esgoto melhorou a fertilidade do substrato, o que proporcionou aumento na biomassa total. Neste estudo, os tratamentos que continham lodo de esgoto em sua composição apresentaram resultados de massa seca da parte aérea, massa seca de raízes e massa seca total estatisticamente superiores às do tratamento com apenas substrato comercial em sua composição.

Fazendo análise da massa seca da parte aérea (MSPA) e da raiz (MSR), Carneiro (1995) constatou que o seu melhor crescimento é importante para dar suporte à biomassa verde produzida pelas plantas, sendo esse crescimento consequência da qualidade das sementes, do tipo e proporção do substrato (componentes físico, químico e biológico) e manejo das mudas no viveiro, além de outros aspectos, como volume do recipiente. Trigueiro e Guerrini (2003), em estudo avaliando a viabilidade do uso de lodo de esgoto como componente do substrato para produção de mudas de eucalipto, verificaram que os tratamentos com $50 \%$ e $60 \%$ de lodo de esgoto resultaram em maior massa seca radicular e da parte aérea das mudas, em comparação com outras porcentagens de lodo de esgoto. Clement e Machado (1997) afirmaram que a incorporação de compostos orgânicos nos substratos pode influenciar na produção de biomassa e das raízes de determinadas espécies florestais. Resultados desses estudos corroboram os dados deste trabalho, em que se verificaram MSPA e MSR maiores nos tratamentos com os componentes orgânicos, pois a adição de uma fonte orgânica de nutriente proporcionou maior retenção de água, melhorou a aeração das raízes e disponibilizou nutrientes para a muda (ARAÚJO; SOBRINHO, 2011).

A razão entre massa seca da parte aérea e raiz é comumente menor em ambiente de baixa fertilidade, podendo ser considerada estratégia da planta para retirar o máximo de nutrientes naquela condição (TEDESCO et al., 1999; CALDEIRA et al., 2000). Então, pode-se inferir que o tratamento-testemunha não proporcionou bom suprimento de nutrientes para as plantas e que os demais tratamentos apresentaram maior teor de nutrientes em razão, principalmente, dos teores de matéria orgânica adicionados pelo lodo de esgoto, casca de arroz carbonizada e palha de café in natura. Alguns pesquisadores defendem que a razão deva ser de 2 para mudas de diferentes espécies (BRISSETE, 1984; DANIEL et al., 1997; CALDEIRA et al., 2000). As médias dessa razão, neste estudo, ficaram abaixo do indicado por esses autores, o que se pressupõe um desequilíbrio no ganho de massa, sendo o ganho de massa seca da parte aérea não acompanhado pelo ganho da massa das raízes.

\section{CONCLUSÃO}

Com base nas características morfológicas avaliadas, os substratos formulados com lodo de esgoto, casca de arroz carbonizada e palha de café in natura proporcionaram maior crescimento das mudas de Chamaecrista desvauxii.

O tratamento formulado com $60 \%$ de lodo de esgoto $+20 \%$ de casca de arroz carbonizada $+20 \%$ de palha de café in natura proporcionou o melhor crescimento das características morfológicas avaliadas: altura, diâmetro do coleto, índice de qualidade de Dickson, massa seca da parte aérea, massa seca do sistema radicular e massa seca total, sendo indicado para a produção de Chamaecrista desvauxii.

\section{AGRADECIMENTOS}

Ao CNPq (Edital MCT/CNPq No 12/2010), pelo auxílio financeiro (bolsa de IC), que possibilitou a realização deste trabalho.

\section{REFERÊNCIAS}

ARAÚJO, A. P.; SOBRINHO, S. P. Germinação e produção de mudas de tamboril (Enterolobium Contortisiliquum) (vell.) morong) em diferentes substratos. Revista Árvore, v.35, n.3, Edição Especial, p.581-588, 2011.

BERNARDINO, D. C. S. et al. Crescimento e qualidade de mudas de Anadenanthera macrocarpa (Benth.) brenan em resposta à saturação por bases do substrato. Revista Árvore, v.29, n.6, p.863-870, 2005.

BRISSETE, J. C. Summary of discussion of about seedling quality. In: SOUTHERN NURSERY CONFERENCES, 1984, Alexandria. Proceedings... New Orleans: USDA, Forest Service/Southern Forest Experiment Station, 1984. p.127-128. 
CALDEIRA, M. V. W. et al. Uso do resíduo do algodão no substrato para produção de mudas florestais. Revista Acadêmica: Ciência Agrária e Ambiental, v.6, p.191-202, 2008a.

CALDEIRA, M. V. W. et al. Composto orgânico na produção de mudas de aroeira-vermelha.

Scientia Agraria, v.9, n.1, p.27-33, 2008 b.

CALDEIRA, M. V. W. et al. Crescimento de mudas de Eucalyptus saligna Smith em função de diferentes doses de vermicomposto. Revista Floresta, v.28, n.1/2, p.19-30, 2000.

CARneiro, J. G. A. Produção e controle de qualidade de mudas florestais. Curitiba: UFPR/FUPEF; Campos, UENF, 1995. 451p.

CLEMENT, C. R.; MACHADO, F. M. Efeito da adubação orgânica na produção de biomassa em quebra-pedra (Phyllanthus stipulatus,

Euphorbiaceae) em Manaus, Brasil. Acta

Amazônica, v.27, n.2, p.73-80, 1997.

DANIEL, O. et al. Aplicação de fósforo em mudas de Acacia mangium. Revista Árvore, v.21, n.2, p.163-168, 1997.

DICKSON, A.; LEAF, A. L.; HOSNER, J. F. Quality appraisal of while spruce and white pine seedling stock in nurseries. Forestry Chronicle, v.36, n.1, p.11-13, 1960 .

\section{EMPRESA BRASILEIRA DE PESQUISA} AGROPECUÁRIA - EMBRAPA. Manual de métodos de análises de solo. 2.ed. Rio de Janeiro: 1997. 212p.

FARIA, S. M. et al. Occurrence of nodulation in the Leguminosae. New Phytology, v.111, p.607-619, 1989.

FAUSTINO, R. et al. Lodo de esgoto como substrato para a produção de mudas de Senna siamea Lam. Revista Brasileira de Engenharia Agrícola e Ambiental, v.9, p.278-282, 2005.

GOMES, J. M. et al. Parâmetros morfológicos na avaliação da qualidade de mudas de Eucalyptus grandis. Revista Árvore, v.26, n.6, p.655-664, 2002.

Revista Árvore, Viçosa-MG, v.37, n.1, p.31-39, 2013
GONÇALVES, J. L. M. et al. Produção de mudas de espécies nativas: substrato, nutrição, sombreamento e fertilização. In: GONÇALVES, J. L. M.; BENEDETTI, V. (Ed.) Nutrição e fertilização florestal. Piracicaba: ESALQ/ USP, 2000. p.309-350.

GONÇALVES, J. L. M.; POGGIANI, F. Substratos para produção de mudas florestais. In: SOLO $96-$ SUELO CONGRESSO LATINOAMERICANO DE CIÊNCIA DO SOLO, 13, 1996, Águas de Lindóia. Resumos expandidos... Águas de Lindóia: SLCS/SBCS, 1996.

GUERRINI, I. A.; TRIGUEIRO, R. M.. Atributos físicos e químicos de substratos compostos por biossólidos e casca de arroz carbonizada.

Revista Brasileira de Ciência do Solo, v.28, n.6,p. 1069-1076, 2004.

HUNT, G. A. Effect of styroblock design and cooper treatment on morphology of conifer seedlings. In: TARGET SEEDLING SYMPOSIUM, MEETING OF THE WESTERN FOREST NURSERY ASSOCIATIONS, GENERAL TECHNICHAL REPORT RM-200, 1990, Roseburg.

Proceedings... Fort Collins: United States Departament of Agriculture, Forest Service, 1990. p.218-222.

KRATZ, D. Substratos renováveis para produção de mudas de Eucalyptus benthamii Maiden et Cambage e mimosa scabrella Benth. 2011. 121f. Dissertação (Mestrado em Ciências Florestais) - Universidade Federal do Paraná, Curitiba, 2011.

MAIA, A. R.; LOPES, J. C.; TEIXEIRA, C. O. Efeito do envelhecimento acelerado na avaliação da qualidade fisiológica de sementes de trigo. Revista Ciência e Agrotecnologia, v.31, n.3, p.678-684, 2007.

MAIA, C. M. B. F. Uso de casca de Pinus e lodo biológico como substrato para a produção de mudas de Pinus taeda. Boletim de Pesquisa Florestal, n.39, p.81-82, 1999.

MARQUES, L. S. et al. Crescimento de mudas de jacaré (Piptadenia gonoacantha J.F. Macbr.) em diferentes tipos de solos e fontes e doses de nitrogênio. Revista Árvore, v.33, n.1, p. 81-92, 2009. 
NÓBREGA, R. S. A. et al. Utilização de biossólido no crescimento inicial de mudas de aroeira (Schinus terebynthifolius Raddi). Revista Árvore, v.31, p.239-246, 2007.

OLIVEIRA, R. B. et al. Produção de mudas de essências florestais em diferentes substratos e acompanhamento do desenvolvimento em campo. Ciência e Agrotecnologia, v.32, n.1, p. 122-128,2008.

PEDROZA, J. P. et al . Produção e componentes do algodoeiro herbáceo em função da aplicação de biossólidos. Revista Brasileira de Engenharia Agrícola e do Ambiente, v.7, n.3, .p. 483-488, 2003.
SOARES, F. C. et al. Consumo de água pela cultura do lírio, cultivado em substratos alternativos em condições de ambiente protegido. Ciencia. Rural [online]. v.42, n.6, p.1001-1006, 2012.

TEDESCO, N.; CALDEIRA, M. V. W.; SCHUMACHER, M. V. Influência do vermicomposto na produção de mudas de caroba (Jacaranda micrantha Chamisso). Revista Árvore, v.23, n.1, p.1-8, 1999.

TRIGUEIRO, R. M.; GUERRINI, I. A. Uso de biossólido como substrato para produção de mudas de eucalipto. Revista Scientia Florestalis, v.64, n.2, p.150-162, 2003. 
